\title{
Non-locally trained doctors: the bottom line
}

This article was published on 17 May 2021 at www.hkmj.org.

\author{
Department of Surgery, LKS Faculty of Medicine, The University of Hong Kong, Hong Kong
}

*Corresponding author: gilberto@hku.hk

Hong Kong Med J 2021;27:172-4

https://doi.org/10.12809/hkmj215110

Doctor's cross-border mobility is on the rise. ${ }^{1}$ To ensure standards, regulatory agencies adopt various criteria for granting licence to practice to nonlocally trained doctors, based on, for example, the provenance of an applicant's medical degree; the passing of a domestic licensing examination is a common but not invariable requirement. ${ }^{2,3}$

That a medical school's standing may serve as a reliable proxy of its graduates' competency and readiness for cross-border practice is a notionally simple but methodologically complex idea. Medical degree programmes, for one, are diverse in their philosophies, designs, and deliverables, whilst "excellence" may stem from teaching and/or research in various forms. Even graduates of the same school may exhibit different levels of workplace performance, depending on the individual's aptitude, and the cultural, socio-economic and service provision environment. Recent growth in medical school number compounds the situationas of February 2021, the World Directory of Medical Schools listed 3416 medical schools worldwide, doubling the estimated figure from two decades prior. ${ }^{4,5}$ Standards vary. ${ }^{6,7}$

A fair, evidence-based, and publicly accountable approach is crucial if the importation without examination of non-locally trained doctors is to achieve its intended goals by gaining political leverage and societal acceptance. Two tools are available: world university rankings and international recognition of accreditation agency.

\section{World university ranking}

Quacquarelli Symonds (QS), ${ }^{8}$ and Times Higher Education (THE) $)^{9}$ produce the most influential rankings of medical schools globally. Both rely on objective, quantitative data (eg, bibliometrics) as well as peer review by academics. The QS assessment is based on six performance indicators; THE uses 13 .

The two systems have been criticised for methodological flaws, propensities for bias, and questionable utility. ${ }^{10,11}$ In the present context, teaching-arguably the main function of medical school-is accorded not more than $30 \%$ weighting by either system. Neither of them assesses curriculum design or pedagogy directly but instead rely on reputational survey. Learner's outcome-the most relevant parameter for non-locally trained doctorsis not explicitly addressed by THE, and is somewhat subsumed under "employer reputation" by QS. Research performance predominates; even metrics such as faculty-to-student ratio can be more related to research than teaching capacity.

This is not to say that research performance and internationalisation would have no bearing on the training of future doctors at medical school: the availability of world-class experts as teachers and mentors, a strong reputation that attracts referrals and patients as training materials, and the greater opportunities for intellectual and experiential exchange can vastly enrich students' learning experiences at top institutions. On the contrary, an institution where staff's career progression hinges solely on bibliometrics is unlikely to incentivise good teaching. Much would depend on the organisational culture-an element perhaps too nebulous to be captured accurately, if at all, by any assessment methods.

Despite differences in methodology, QS and THE are usually, broadly in agreement. Based on this author's brief analysis of their latest findings (published in 2020 for 2021), each lists 101 schools in the top 100 (there is sharing of the 100th position in both). Of the combined 202 entries, 76 schools appear under both QS and THE; 25 appear under QS only and 25 under THE only, yielding a total of 126 schools making the top 100 according to at least one of the rankings. Incongruence occurs mainly within the 51 to 100 range, where $88 \%$ of the "QS-only" or "THE-only" top 100 schools are found, and where divergence between the two systems in terms of an individual school's ranking is more pronounced. The degree of correlation is high at the top, with nine schools ranked top- 10 by both QS and THE. Note that the rankings do change, sometimes considerably, from year to year.

The United States, the United Kingdom, and Canada feature a high number of top 100 schools (Table). And it is probably not by coincidence that graduates from these countries (plus New Zealand and Ireland) may obtain provisional registration, examination-free, through the Competent Authority Pathway of the Australian Medical Board, and gain full registration after 12 months of supervised practice. $^{2}$ 
The Singapore Medical Council offers a similar examination-free pathway to graduates from 103 foreign schools. ${ }^{3}$ Ninety-one of these were ranked top-100 by either QS or THE, and include 68 of the 76 schools found on both top 100 lists (Table). The present number of 103 is a reduction from previous, having regards to national and international rankings of universities as well as performance of conditionally registered doctors; most of the schools that have been dropped fall outside the top 100 lists. ${ }^{12}$

\section{World Federation for Medical Education Recognition Programme}

Accreditation of a medical school by the relevant domestic authority alone does not guarantee quality; it is necessary that the accreditation system itself operates in a robust, transparent, and normreferenced way. To this end, the World Federation for Medical Education (WFME) - a not-for-profit non-governmental global organisation-conducts a Recognition Programme to evaluate the legal standing, accreditation process, post-accreditation monitoring, and decision-making processes of an accreditation agency. The WFME Recognition Status of an agency "confers the understanding that the quality of medical education in its accredited schools is at an appropriate and rigorous standard". The WFME does not accredit medical schools. ${ }^{13}$

Presently, there are 23 agencies with Recognition Status; 15 are applying. The programme is afforded significance as suggested by the latest policy of the United States Educational Commission for Foreign Medical Graduates requiring all individuals applying for Certification to come from a medical school accredited by a WFME-recognised agency. ${ }^{14}$ Application for WFME recognition is voluntary, however, and the lack of Recognition Status says little about an agency. Indeed, nine of the 24 states or regions on the QS/THE top 100 lists (notably the United Kingdom) do not have a WFMErecognised agency, and not all schools accredited by a WFME-recognised agency are ranked highly (Table).

In sum, state policies on examination-free entry of non-locally trained doctors, where deemed appropriate, may take a country-specific or a rankings-based approach. World university rankings are accessible and intelligible tools for gauging the quality of a medical school and its graduates' competency but do not by themselves alone offer a fool-proof guide to a doctor's readiness for crossborder practice; factors such as language proficiency, work experience, and higher qualifications are pertinent. The QS and THE produce fairly consistent results particularly at the top end of the spectrum
TABLE. Top 100 medical schools by state or region

\begin{tabular}{|c|c|c|c|c|}
\hline State/region & $\begin{array}{l}\text { Quacquarelli } \\
\text { Symonds }\end{array}$ & $\begin{array}{l}\text { Times Higher } \\
\text { Education }\end{array}$ & $\begin{array}{c}\text { Foreign } \\
\text { schools } \\
\text { recognised by } \\
\text { SMC with top } \\
100 \text { positions }\end{array}$ & $\begin{array}{l}\text { WFME- } \\
\text { recognised } \\
\text { accreditation } \\
\text { agency }\end{array}$ \\
\hline Australia & 7 & 6 & 7 & Yes \\
\hline Austria & 1 & 0 & 1 & No \\
\hline Belgium & 1 & 1 & 1 & Yes \\
\hline Brazil & 1 & 1 & 0 & Yes \\
\hline Canada & 7 & 7 & 7 & Yes \\
\hline Denmark & 2 & 1 & 1 & No \\
\hline Finland & 1 & 1 & 1 & No \\
\hline France & 2 & 2 & 1 & No \\
\hline Germany & 4 & 6 & 3 & Applying \\
\hline Hong Kong & 2 & 2 & 2 & No \\
\hline Italy & 3 & 0 & 0 & Applying \\
\hline Japan & 3 & 3 & 3 & Yes \\
\hline Mainland China & 3 & 5 & 4 & Yes \\
\hline The Netherlands & 6 & 7 & 4 & Yes \\
\hline New Zealand & 1 & 0 & 1 & Yes \\
\hline Singapore & 1 & 1 & - & No \\
\hline South Africa & 1 & 2 & 0 & No \\
\hline South Korea & 3 & 4 & 2 & Yes \\
\hline Spain & 1 & 0 & 1 & Applying \\
\hline Sweden & 3 & 1 & 3 & No \\
\hline Switzerland & 3 & 3 & 4 & Applying \\
\hline Taiwan & 1 & 1 & 1 & Yes \\
\hline United Kingdom & 15 & 12 & 15 & No \\
\hline United States & 29 & 35 & 29 & Yes \\
\hline Total & 101 & 101 & 91 & \\
\hline
\end{tabular}

Abbreviations: SMC = Singapore Medical Council;WFME = World Federation for Medical Education

although the inherent year-to-year instability would require some mitigation. The WFME Recognition Programme, concerned with national accreditation standards at large, brings nothing extra to the table. The matter, should it ever come into play anywhere, has to be part art and part science topped off with a healthy dose of courage and common sense-the bottom line being that decisions ought to be made by a professional, and not an executive, body with legally conferred power and independent status based on professional, and none other, considerations.

\section{Author contributions}

The author is solely responsible for the writing of this paper.

\section{Conflicts of interest}

The author has disclosed no conflicts of interest. 


\section{References}

1. World Health Organization. Health Workforce International platform on health worker mobility. Available from: https://www.who.int/hrh/migration/int-platformhw-mobility/en/. Accessed 14 Feb 2021.

2. Medical Board of Australia. International medical graduates. Available from: https://www.medicalboard.gov. $\mathrm{au} /$ Registration/International-Medical-Graduates.aspx. Accessed 14 Feb 2021.

3. Singapore Medical Council. International medical graduates. Available from: https://www. healthprofessionals.gov.sg/smc/becoming-a-registereddoctor/register-of-medical-practitioners/internationalmedical-graduates. Accessed 10 Feb 2021.

4. World Directory of Medical Schools. Available from: https://www.wdoms.org. Accessed 13 Feb 2021.

5. Eckhert NL. The global pipeline: too narrow, too wide or just right? Med Educ 2002;36:606-13.

6. van Zanten M, Norcini JJ, Boulet JR, Simon F. Overview of accreditation of undergraduate medical education programmes worldwide. Med Educ 2008;42:930-7.

7. Duvivier RJ, Boulet JR, Opalek A, van Zanten M, Norcini J. Overview of the world's medical schools: an update. Med Educ 2014;48:860-9.

8. QS World University Rankings-methodology. Available from: https://www.topuniversities.com/qs-world- university-rankings/methodology. Accessed 14 Feb 2021.

9. Times Higher Education. The World University Rankings 2021: methodology. Available from: https://www. timeshighereducation.com/world-university-rankings/ world-university-rankings-2021-methodology. Accessed 14 Feb 2021.

10. Ioannidis JP, Patsopoulos NA, Kavvoura FK, et al. International ranking systems for universities and institutions: a critical appraisal. BMC Med 2007;5:30.

11. Soh K. What the overall doesn't tell about world university rankings: examples from ARWU, QSWUR, and THEWUR in 2013. J Higher Educ Policy Manage 2015;37:295-307.

12. UniGlobal Education. 57 universities to be removed from the list of Singapore Medical Council (SMC) approved overseas medical schools. Available from: https://uniglobal. sg/2019/04/18/57-universities-to-be-removed-fromthe-list-of-singapore-medical-council-smc-approvedoverseas-medical-schools/. Accessed 17 Feb 2021.

13. World Federation for Medical Education. WFME recognition programme. Available from: https://wfme.org/ accreditation/recognition-programme/. Accessed 16 Feb 2021.

14. Shiffer CD, Boulet JR, Cover LL, Pinsky WW. Advancing the quality of medical education worldwide: ECFMG's 2023 medical school accreditation requirement. J Med Regul 2019;105:8-16.

\section{Call for Papers: Special Section "Healthcare in Mainland China"}

\section{Section Editors}

Hong Kong Med J 2021;27:174

Yaojiang Shi, Hao Xue, Martin CS Wong

In order to promote high-quality research from mainland China among medical professionals in Hong Kong, the Hong Kong Medical Journal (HKMJ) Editorial Board has undertaken to launch a Special Section in the Journal titled "Healthcare in Mainland China". This section will first feature in the December 2021 issue of HKMJ.

The Editorial Board would like to invite submissions of Original Articles for consideration for inclusion in this "Healthcare in Mainland China" special section on the following topics:

- Primary care in mainland China

- Population health in mainland China

- Other original research that will be of interest to HKMJ readers

All manuscripts submitted for consideration must follow the HKMJ Guide for Authors (https://www.hkamedtrack.org/ hkmj/guide_for_author). All research manuscripts submitted to HKMJ undergo rigorous double-blind peer review.

Authors should submit papers for the "Healthcare in Mainland China" Special Section via our online submission system: http://www.hkamedtrack.org/hkmj 